\title{
Using Throughput Accounting for Cost Management and Performance Assessment: Constraint Theory Approach
}

\author{
Hatem Karim Kadhim, Karar Jasim Najm, Hayder Neamah Kadhim \\ Department of Accounting, Faculty of Administration and Economics, University of Kufa, Najaf, Iraq
}

\begin{abstract}
The paper aims to use throughput accounting as an approach for developing cost accounting systems in the modern manufacturing environment to evaluate the organization performance. The sample consists of (60) persons in organization for examining the hypotheses. The findings show that information provided by throughput accounting helps in measuring costs and evaluate the efficiency and effectiveness of performance in the organization. This approach supports planning and control processes to maximize throughput and reduce inventory levels. The use of Throughput Accounting under the Theory of Constraints leads to finding solutions to bottlenecks that affect the efficiency and effectiveness of performance.
\end{abstract}

Keywords - Throughput Accounting, Theory of Constraints, origination's performance.

\section{Introduction}

Recently, a cost accounting system has been required to adapt to changes in the contemporary environment in order to manage scarce resources, bottlenecks and production constraints. Throughput Accounting uses the principle of constraints as an introduction to the implementation of the cost accounting system.

DOI: 10.18421/TEM92-45

https://doi.org/10.18421/TEM92-45

Corresponding author: Karar Jasim Najm, Department of Accounting, Faculty of Administration and Economics, University of Kufa, Najaf, Iraq.

Email: kararj.aleesawe@gmail.com

Received: 08 February 2020.

Revised: 10 May 2020.

Accepted: 17 May 2020.

Published: 27 May 2020.

(cc) BY-NC-ND(C) 2020 Hatem Karim Kadhim, Karar Jasim Najm \& Hayder Neamah Kadhim; published by UIKTEN. This work is licensed under the Creative Commons Attribution-NonCommercial-NoDerivs 4.0 License.

The article is published with Open Access at www.temjournal.com
This approach provides management cost information in line with the current manufacturing environment and limited resources to improve the operational performance of origination. It reduces throughput time, operating costs and inventory. The beginning of the transition period is in the midseventies from the last century in the area of finance and administrative science inside Goldratt's writings. In the early 1990s, Throughput Accounting emerged as a result of the development of the Theory of Constraint. Management needs knowledge in the modern manufacturing environment. Throughput Accounting is one of the modern approaches to cost measurement and performance assessment. This approach provides a comprehensive vision of the organization and encourages consistency between the different departments and activities of the organization [1]. The importance of research stems from the role of Throughput Accounting in addressing the negative effects of misuse of resources in restricted operations, which leads to a decrease in productivity and quality of output. Throughput Accounting is one of the management accounting methods that contributes to the provision of information, cost measurement and performance assessment of the organization. The research issue is that many of the companies in Iraq are suffering from issues related to the constraints faced during the production process. The problems impede the continuous flow of production. These organizations seek to raise the level of performance and remain in the labor market. This strategy leads to rapid changes in the level of quality management, cost reduction, production efficiency and maximization of productivity. The presence of these constraints restricts the efficiency of the organizations that have contributed to the use of Throughput Accounting to control the constraints and enhance the operating performance of the organizations.

\section{Literature Review}

Theory of Constraints (TOC) originated as an effective management theory that offers practical solutions to various complex problems, including the 
problem of product mixing. Researchers have demonstrated the superiority of various methods of improvement over events based on the table of contents in the "fixed" product mix issue. Nonetheless, the content table could not be interpreted as a whole, i.e. considering the effect of resource and comment loop dependence, and, most significantly, statistical variations occur in any complex work environment [2]. In this context, [3] attempts to implement each of the Activity-based Costing (ABC) to determine and allocate costs accurately and implement Theory of Constraints (TOC) with the help of Microsoft Excel. [4] examines applying the TOC Thinking Process: A case study in the government sector. they show the importance of the thinking approach in addressing constraints in the water maintenance department in water services organizations and work to build an environment free of errors and problems by identifying constraints and addressing them through the components of the Thinking approach. [5] uses the Theory of Constraints under the $\mathrm{ABC}$ approach to allocate costs accurately and identify obstacles in the production process and unexploited energy by using a mathematical model. In [6], analysis using the Throughput Accounting (TA) metrics can be paired with the Six Sigma's research. The goal is to achieve convergence between the Throughput Accounting and Six Sigma in order to improve the respective metrics.

The Theory of Constraints (TOC) is unique in its work by focusing on the efficiency of the production process. This concept was first developed by Goldratt and Cox in 1986 in the United States. [7] introduced with his book "The Goal" and developed this concept in 1990 eventually. Theory of Constraints is the common name in the United States [7], [8]. [9] defines the Theory of Constraints as an administrative approach aimed at maximizing longterm profit by addressing organizational bottlenecks or scarce resources in organization. [10] states that it is the strategy of managing the organization to improve the time of the product cycle for ensuring the optimal flow of production. While [11] defines the TOC as a description of the methods used to maximize operating income when facing operations to areas representing bottlenecks and other areas that do not represent bottlenecks. [11] also defines it: a system that seeks to determine how decisions are made and how to deal with the constraints for the production process which can be internal or external [12]. On the other hand, [13] shows that the TOC is an administrative philosophy that aims to achieve continuous improvement through the process and management of constraints that prevent management from achieving its goals in the short term. The researchers note that the theory of constraints is an integrated system consisting of a set from principles, concepts and tools that help organizations to identify and address the constraints and bottlenecks to achieve their goals and enhance their profits. According to [14], [15], [16], there are many benefits for the Theory of Constraints that can be summarized as the following:

- productivity increases to achieve the highest throughput as well as reduce time and operating costs.

- TOC helps to attain the continuous improvement of the system performance in organizations.

- Increasing the flow rates by solving the fundamental constraints and meet the actual demand for goods or services.

- TOC reduces the work in process inventory by removing the bottlenecks facing the production process to reduce the accumulation of inventory between activities.

- It is a tool that helps to work in a team spirit in different areas of the organization which is reflected positively on the identification and removal of constraints.

- The development of strategic plans and operational decision making is facilitated by the identification of bottlenecks and constraints.

- Optimal use of resources leads to improving the profits and sales within the organization.

Whereas, many studies such as [17], [18], [19] indicate that the theory of constraints principles include the following:

- The level of outputs achieved at the level of unrestricted resources is determined by the level of the restricted system resources.

- The benefit and effectiveness of the system are not synonymous i.e., benefit is the operation of unrestricted resources at full capacity to reduce loss. While effectiveness is the extent of the system ability to achieve its goals regardless of the capacities level used in the production process.

- The throughput of time achieved at the level of restricted resources equals the increase in the rate of restricted resources outputs.

- The margin of time achieved at the level of unrestricted resources is considered complete illusion because the increase in idle time means increased inventory.

- The transformation batch may not equal the production batch. The transformation batch is the amount of resources transferred from the production process to the subsequent and usually less than the production batch represented by the amount of resources produced between the work centers. 
- The production batch must be changed because of the different capacities between production processes. Bottlenecks or constraints occur in the production process.

Moreover, [20], [21], [22] identify the most important steps to implement the Theory of Constraints as follows:

- Identify constraints of the system: Constraints are limiting the optimal utilization of resources and represent the bottleneck in the system. There may be physical constraints such as materials, machinery, level of demand or administrative constraints such as procedures, methods and policies.

- Define how to exploit the constraints: Make maximum use of the constraint and work to exploit it in the best form. If the constraint is a raw material, it must be sure that there is no loss or damage. If the constraint is a policy, it must be replaced by another policy that achieves the same goal.

- Integration of all other elements to exploit the constraint: Find a kind of integration and interdependence between restricted and unrestricted resources. The processing of bottlenecks is avoided for the unrestricted resource and the formation of a new constraint.

- Working to raise the constraint: Through increasing the production capacity of the resource restricted and increase market share or training of workers or increase their skills.

- Evaluation and processing of the constraint activity and return to the first step.

The process of continuous improvement to overcome a certain constraint shows us another constraint. Return to the first step to search about the underlying causes of this constraint and improve the system. The following figure illustrates the steps to implement the Theory of Constraints to manage the constraints.

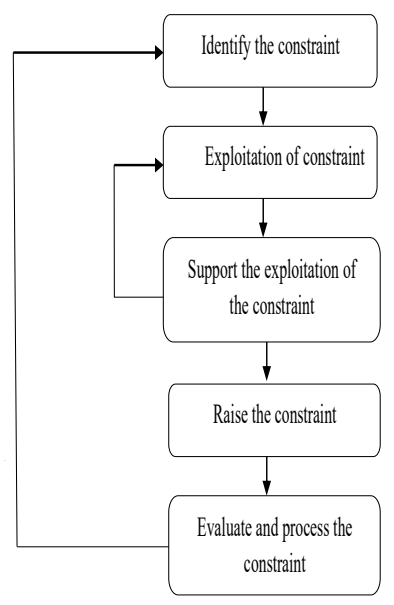

Figure 1. The Theory of Constraints

\section{Throughput Accounting}

The objective of the organization is gaining money and performance measures. The progress shows the achieved goal. As a result, the current measurements of cost accounting lead either to loss of throughput, increase in inventory or operating expenses [23]. This is inconsistent with the objective of the organization. Throughput Accounting requires the provision of more appropriate tools to stimulate these organizations. This approach contains the direct materials cost of the product only. The other costs are fixed because they cannot be allocated to the products [24]. Throughput Accounting is a modern concept in managerial accounting to support Theory of Constraints. The Throughput Accounting provides measurements to implement the main concepts of the Theory of Constraints [25]. Also, it helps identify and measure the cost of production, sales and increase productivity. At the same time, to reduce inventory and operating costs and help management to make optimal decisions [6]. The main concept of Throughput Accounting is use of profitability analysis at the level of the organization rather than the profit margin analysis at the product level. In contrast, the traditional cost accounting is collected costs from all departments of the production process. It is allocated in different ways to products. The cost is subtracted from the selling price, and the profit margin of the product is reached [26]. Throughput Accounting is defined as: a performance measurement method that builds on the relationships between production, costs and throughput. The products cost determined according to the Throughput Accounting depending on both the main products and resources [27]. They also define it as an administrative tool that operates partly on the Theory of Constraints. The management focuses mainly to maximize profits rate by processing on bottlenecks [28]. Hansen defines it: An accounting approach to evaluate the organization ability to maximize the effectiveness of the activity's achievement through the use of financial measures. The optimal utilization of restricted resources leads to attaining the goal within a given period [29]. [30] defines it as: the system consists of a number from dependent variables to achieve goal units. The system reduces application limitations and improves performance by using system constraints. While Maynard defines it as: The accounting system seeks to maximize the return on the restricted resource activity [31]. The researchers note that Throughput Accounting use to evaluate the company's performance effectively. It reaches the ultimate goal of revenue generation by minimizing constraints and bottlenecks in the work environment. Throughput Accounting is not a system for measuring and allocating costs, such as standard 
costs and activity-based costing. It is a measure of the added value from the organization's cash inflows in the form of revenues or sales. The importance of this approach shows in continuous improvement to maximize throughput rather than reduce costs.

\section{The Role of Throughput Accounting in Cost Measurement and Performance Assessment}

Throughput Accounting is based on dividing the structure of the manufacturing costs elements according to their behavior to the raw material as the only variable element. The rest of the elements are grouped into a single group called operating expenses which are fixed costs in the short term and are predetermined costs. The quantity of inputs needed to manufacture the product unit which are manufactured and then sold and should not exceed; or less than a certain amount because in case of shortage the product is not completed. In the case of increasing it will be transferred into warehouses and the organization costs are increasing due to retention, damage and loss. The major developments in the modern manufacturing environment have led to increased investments in machinery and equipment and the disappearance of the direct labor component in the structure of industrial costs. Accordingly, raw material costs became the only variable component of costs as a result of the direct labor cost shifting to the fixed cost category [30]. It identifies the strengths and weaknesses of the organization in a fast and flexible manner [32]. [30] indicate that the performance measures that depend on Theory of Constraints are;

- Performance measures at the level of organization performance such as net profit, return on capital invested and cash flow.

- Performance measures at the level of internal performance such as internal operations surplus i.e., sales revenue less the cost of direct materials and inventory. It represents any invested cash through the organization in the purchase of materials and assets. These measures also include the operating expenses that represent the cash paid by organizations to convert the inventory into internal operations surplus.

- Performance measures at the process level using detailed cost information.

- The theory of constraints concerns short-term measurements and neglects long-term vision required by strategic decisions.
- Time is the main element in the Throughput Accounting approach for the purpose of applying costs on the units produced. It is called the throughput time and represents the time spent to convert the raw material to a finished product and sales.

In addition, the Throughput Accounting did not measure cost and evaluate performance according to the conceptual framework of measurement. It links the amount of throughput achieved and the resources consumed to achieve that throughput.

\section{Research Methodology}

This study depends on a basic hypothesis that the use of Throughput Accounting contributes to the measurement of cost and evaluate the efficiency and effectiveness of the organization performance at the application of the Theory of Constraints and adapted to the contemporary business environment.

The sample contains (60) questionnaires distributed to the accounting, administrative, technical, engineering and production designers' staffs at the State Company for Electrical Industries in Waziriya. The period of application for the questionnaire was during 9/2019-11/2019. The State Company for Electrical Industries in Waziriya is one of the factories belonging to the General Company for Southern Cement, which is one of the formations affiliated to the Ministry of Industry and Minerals. It is located in Baghdad province. The company produces the following products: fans, motors, refrigerators, heaters, air conditioners and various electrical equipment.

The data used in this study were obtained by analyzing questionnaires distributed over the sample, including administrative, financial, productive and engineering staff in the factory. The authors determine the most important questions related to the research. The individual's opinions of the research sample identify and test the hypothesis of the research using the fifth Likert method. It depend on a set of statistical indicators to conduct statistical analysis, as follows: Test the hypothesis of research, which states: The use of Throughput Accounting contributes to the measurement of cost and evaluate the efficiency and effectiveness of the economic unity performance at the application of the Theory of Constraints and adapted to the contemporary business environment. 
Table 1. Indicators of individual responses for hypothesis testing

\begin{tabular}{|c|c|c|c|c|c|}
\hline \multirow[b]{2}{*}{ \# } & \multirow[b]{2}{*}{ Items } & \multicolumn{4}{|c|}{ Statistical Indicators } \\
\hline & & 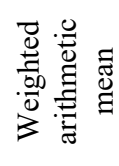 & 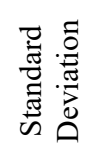 & 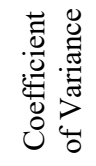 & 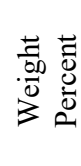 \\
\hline 1 & $\begin{array}{l}\text { The use of Throughput } \\
\text { Accounting leads to the } \\
\text { provision of accurate } \\
\text { cost measures in the } \\
\text { organization. }\end{array}$ & $\begin{array}{l}\hat{8} \\
\infty \\
\dot{m}\end{array}$ & $\stackrel{\nabla}{\stackrel{\Xi}{\Xi}}$ & 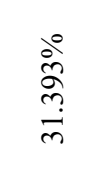 & 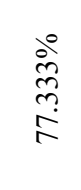 \\
\hline 2 & $\begin{array}{l}\text { Throughput } \\
\text { Accounting provides } \\
\text { relevant information on } \\
\text { the time of restricted } \\
\text { activities achievement. }\end{array}$ & $\begin{array}{l}\stackrel{\nabla}{\nabla} \\
\dot{\nabla}\end{array}$ & $\begin{array}{l}\stackrel{0}{\circ} \\
\stackrel{0}{0}\end{array}$ & $\stackrel{\substack{n \\
m}}{\stackrel{n}{n}}$ & 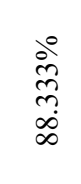 \\
\hline 3 & $\begin{array}{l}\text { Throughput } \\
\text { Accounting works on } \\
\text { to provide relevant cost } \\
\text { information with the } \\
\text { modern manufacturing } \\
\text { environment. }\end{array}$ & $\begin{array}{l}\text { 尺 } \\
\stackrel{0}{0} \\
\dot{+}\end{array}$ & $\begin{array}{l}\stackrel{\circ}{\rightleftharpoons} \\
\rightleftharpoons\end{array}$ & $\begin{array}{l}\stackrel{\circ}{+} \\
\text { in } \\
\infty \\
\stackrel{i}{d}\end{array}$ & $\frac{\dot{\delta}_{0}^{\circ}}{\dot{\delta}}$ \\
\hline 4 & $\begin{array}{l}\text { The product applies by } \\
\text { the cost of direct } \\
\text { materials only without } \\
\text { the other operating } \\
\text { costs. It is useful for } \\
\text { measures of the added } \\
\text { value of the inflows } \\
\text { generated by the } \\
\text { revenues. }\end{array}$ & $\begin{array}{l}\bar{D} \\
\dot{+}\end{array}$ & $\stackrel{\Xi}{\beth}$ & 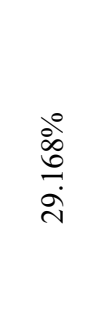 & $\begin{array}{l}\stackrel{0}{m} \\
\stackrel{n}{\infty} \\
\infty\end{array}$ \\
\hline 5 & $\begin{array}{l}\text { Assisting organization } \\
\text { in the measurement } \\
\text { and evaluation of } \\
\text { performance through } \\
\text { the information } \\
\text { provided by } \\
\text { Throughput } \\
\text { Accounting. }\end{array}$ & $\begin{array}{l}\stackrel{\overbrace{}}{~} \\
\text { † }\end{array}$ & ָ̃ & $\begin{array}{l}\stackrel{0}{\infty} \\
\stackrel{\sim}{N} \\
\stackrel{\sim}{\sim}\end{array}$ & $\begin{array}{l}\stackrel{0}{8} \\
\delta \\
\dot{0} \\
\dot{\infty}\end{array}$ \\
\hline 6 & $\begin{array}{l}\text { There is a need to } \\
\text { develop cost systems } \\
\text { for give detailed } \\
\text { information to evaluate } \\
\text { current and future } \\
\text { performance, improve } \\
\text { the measurement and } \\
\text { evaluation of } \\
\text { performance. }\end{array}$ & $\begin{array}{l}\hat{b} \\
\text { v }\end{array}$ & $\begin{array}{l}\stackrel{\infty}{\circ} \\
\hat{0}\end{array}$ & $\begin{array}{l}\stackrel{0}{i n} \\
\stackrel{\infty}{\sim} \\
\ddot{v}\end{array}$ & $\begin{array}{l}\stackrel{0}{\infty} \\
\text { ñ } \\
i n \\
\infty\end{array}$ \\
\hline 7 & $\begin{array}{l}\text { The development of } \\
\text { cost systems } \\
\text { contributes to the } \\
\text { provision of integrated } \\
\text { information on the } \\
\text { profitability of the } \\
\text { product, the customer } \\
\text { and the company. }\end{array}$ & $\begin{array}{l}\stackrel{\overbrace{}}{~} \\
\stackrel{+}{+}\end{array}$ & $\begin{array}{l}\circ \\
\stackrel{0}{0} \\
0\end{array}$ & $\begin{array}{l}80 \\
8 \\
\infty \\
i j\end{array}$ & $\begin{array}{l}\stackrel{\circ}{8} \\
8 \\
\dot{+}\end{array}$ \\
\hline 8 & $\begin{array}{l}\text { Increased competition } \\
\text { requires the } \\
\text { development of current } \\
\text { cost systems. }\end{array}$ & $\begin{array}{l}\stackrel{\bigcirc}{+} \\
\dot{+}\end{array}$ & $\hat{\text { }}$ & $\begin{array}{l}\stackrel{0}{\infty} \\
\infty \\
\\
\end{array}$ & $\begin{array}{l}\text { oें } \\
\delta \\
\dot{\delta} \\
\infty\end{array}$ \\
\hline
\end{tabular}

\section{Throughput}

Accounting

contributes to the

development of cost

systems in order to

provide relevant

information for the

purposes of planning,

control and evaluation

of performance.

The organization

management is

concerned with the use

of Throughput

Accounting to find

10 solutions of the

bottlenecks and

constraints that affect

the efficiency and

effectiveness of

performance.

Throughput

Accounting

11 contributes to the

identification of

unused capacity.

There is a role for

Throughput

Accounting in

12 identifying

unnecessary activities

that are not add value

Throughput

Accounting under the

Theory of Constraints

13 helps reduce costs and

maximizes

profitability.

Throughput

Accounting

contributes to

14

determining of

minimum inventory

levels.

Throughput

Accounting

contributes to the

provision of many

advantages that lead to

the promotion of

competitiveness in the

market.

Mean

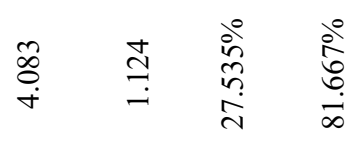

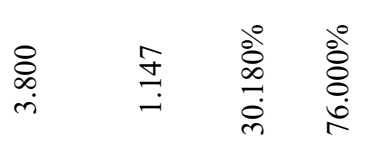

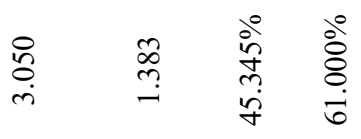

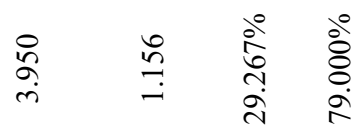

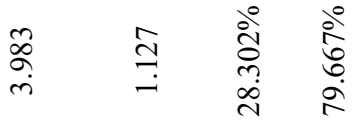

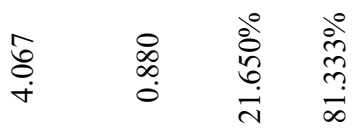

\section{Results and Discussion}

Results of Table 1. including 15 questions. It indicates that the overall response rate of the sample was 80.756 percent with a weighted mean of 4.038 and a standard deviation of 1.062 and a coefficient of variation of 26.823 percent. The tenth item is the most prominent item that contributes to the 
enrichment of this variable: (Organization management is concerned with the use of Throughput Accounting to find solutions to bottlenecks and constraints that affect performance efficiency and effectiveness). Severity of response 90.333 per cent and weighted mean 4.517 , standard deviation 0.676 vs. coefficient of variance 14.973 per cent. The next item is the second item: (Throughput Accounting offers relevant information on the period of minimal task achievement) as the magnitude of the response of 88.333 per cent on a weighted mean of 4.417 and the standard deviation of 0.766 on a coefficient of variance of 17.335 per cent on a weighted mean of 17.335 per cent. Whereas the lowest percentage in this variable is the twelfth paragraph as the severity of the response of $61 \%$ with a weighted mean of 3,050 and a standard deviation of 1,383 as against a coefficient of variation of 45,345 per cent. The following table shows the test $(\mathrm{T})$ for one sample of the research hypothesis variables at the level of significance 5 per cent and the degree of freedom 59 and all the research variables.

Table 2. $T$ test results of the research variables

\begin{tabular}{||ccc||}
\hline Variables & Calculated (T) & Tabulated(T) \\
1 & 5.530 & 1.671 \\
2 & 14.333 & 1.671 \\
3 & 7.035 & 1.671 \\
4 & 6.722 & 1.671 \\
5 & 9.097 & 1.671 \\
6 & 9.919 & 1.671 \\
7 & 8.558 & 1.671 \\
8 & 8.220 & 1.671 \\
9 & 7.464 & 1.671 \\
10 & 17.372 & 1.671 \\
11 & 5.403 & 1.671 \\
12 & 0.280 & 1.671 \\
13 & 6.365 & 1.671 \\
14 & 6.756 & 1.671 \\
15 & 9.385 & 1.671 \\
Mean & 8.163 & 1.671 \\
\hline \hline
\end{tabular}

(df=59, significant level 5\%)

It appears from the table above that the value of (T) estimated is greater than the value of $(\mathrm{T})$ shown. The degree of freedom 59 and the level of significance 5 per cent for the variables of this hypothesis, as well as the general rate of these variables, where the value of $(\mathrm{T})$ is calculated 8.163.
It is greater than the value of $(\mathrm{T})$ filed 1.671 with a degree of freedom 59 and a level of significance 5 per cent. This leads to the acceptance of the research hypothesis, which states that: the use of Throughput Accounting contributes to cost measurement and evaluates the efficiency and effectiveness of the performance of economic unity in applying the Theory of Constraints and adapted to the current business environment.

\section{Conclusion}

The research focuses on the use of Throughput Accounting as an approach to the implementation of cost accounting systems in the modern manufacturing climate. Measures expenses and reviews the performance of the company. The importance of research stems from the role of Throughput Accounting in resolving the negative effects of abuse of capital in restricted activities. The benefit of Throughput Accounting handles constraints and calculates costs in the philosophy of the implementation of constraints and in accordance with the patterns in modern management accounting. The information provided by Throughput Accounting helps to measure costs and to evaluate the efficiency and effectiveness of the organization's performance. This helps to support planning and management processes by optimizing achievement and reducing inventory levels. The use of Throughput Accounting in the context of the theory of constraints leads to solutions to bottlenecks that affect the efficiency and efficiency of performance. Results of the statistical analysis of the study have shown that the general average of the research hypothesis variables in which the value of $(\mathrm{T})$ measured 8.163 is greater than the value of $(\mathrm{T})$ defined 1.671 with a degree of freedom 59 and a level of significance 5 per cent. To accept this hypothesis, which states that: the use of Throughput Accounting leads to cost calculation and tests the efficiency and effectiveness of the results of economic unity in applying the principle of constraints and adapted to the current business setting. Necessary to benefit from the information provided by Throughput Accounting for the treatment of bottlenecks, reduce costs and decrease inventory. Reducing the time required for restricted tasks and maximizing capacity utilization by preventing time loss. Helps top management to apply Throughput Accounting as one of the new management accounting methods. 


\section{References}

[1]. Kbelah, S. I., Amusawi, E. G., \& Almagtome, A. H. (2019). Using Resource Consumption Accounting for Improving the Competitive Advantage in Textile Industry. Journal of Engineering and Applied Sciences, 14(2), 575-382.

[2]. Hilmola, O. P., \& Gupta, M. (2015). Throughput accounting and performance of a manufacturing company under stochastic demand and scrap rates. Expert Systems with Applications, 42(22), 84238431.

[3]. Perkins, D., Stewart, J., \& Stovall, S. (2002). Using Excel, TOC, and ABC to solve product mix decisions with more than one constraint. Management Accounting Quarterly, 3(3), 1-10.

[4]. Shoemaker, T. E., \& Reid, R. A. (2005). Applying the TOC thinking process: a case study in the government sector. Human Systems Management, 24(1), 21-37.

[5]. Tsai, W. H., Kuo, L., Lin, T. W., Kuo, Y. C., \& Shen, Y. S. (2010). Price elasticity of demand and capacity expansion features in an enhanced ABC product-mix decision model. International Journal of Production Research, 48(21), 6387-6416.

[6]. Aghili, S. (2011). Throughput metrics meet six sigma. Management Accounting Quarterly, 12(3), 12.

[7]. Wilks, C., \& Burke, L. (2007). Management Accounting: Decision Management. Elsevier.

[8]. Amusawi, E. G., Almagtome, A. H., \& Shaker, A. S. (2019). Impact of Lean Accounting Information on The Financial performance of the Healthcare Institutions: A Case study. Journal of Engineering and Applied Sciences, 14(2), 589-399.

[9]. Hilton, R. W. (1999). Managerial accounting (p. 568). Irwin/McGraw-Hill.

[10]. Brown, C. A., \& Doran, D. T. (2007). The relative accuracy of allocating service departments' cost to production departments under the step method. The Journal of Cost Analysis \& Management, 9(1), 1-14.

[11]. Horngren, C. T., Foster, G., Datar, S. M., Rajan, M., Ittner, C., \& Baldwin, A. A. (2010). Cost accounting: A managerial emphasis. Issues in Accounting Education, 25(4), 789-790.

[12]. Aryanezhad, M. B., Badri, S. A., \& Rashidi Komijan, A. (2010). Threshold-based method for elevating the system's constraint under theory of constraints. International Journal of Production Research, 48(17), 5075-5087.

[13]. CrFA, C. F. F. (2011). Process improvement in the public sector: A case for the theory of constraints. The Journal of Government Financial Management, 60(2), 40.
[14]. Horngren, C. T. (2009). Cost accounting: A managerial emphasis, 13/e. Pearson Education India.

[15]. Evans, J. R. (1997). Production, operations management: quality, performance, and value. West.

[16]. Waller, D. (1999). Operations management: a supply chain approach (No. hal-02297985).

[17]. Otley, D. (1999). Performance management: a framework for management control systems research. Management accounting research,10(4), 363-382.

[18]. Groop, J. (2012). Theory of constraints in field service: factors limiting productivity in home care operations. [Doctoral Dissertation].

[19]. Haykin, S. (1994). Neural networks: a comprehensive foundation. Prentice Hall PTR.

[20]. Hennessy, J. L., \& Patterson, D. A. (2011). Computer architecture: a quantitative approach. Elsevier.

[21]. Wong, B. B., \& Kokko, H. (2005). Is science as global as we think?. Trends in ecology \& evolution, 20(9), 475-476.

[22]. Rosenthall, S., \& Horn, L. (1997). Vowel/glide alternation in a theory of constraint interaction. Taylor \& Francis.

[23]. De Souza, F. B., \& Pires, S. R. (2010). Theory of constraints contributions to outbound logistics. Management Research Review.

[24]. Blocher, E. J., Stout, D. E., \& Cokins, G. (2010). Cost management: A strategic emphasis. Includes index.

[25]. Hutchinson, R. (2007). The impact of time-based accounting on manufacturing performance [Doctoral dissertation, University of Toledo].

[26]. Bragg, S. M. (2012). Throughput accounting: a guide to constraint management. John Wiley \& Sons.

[27]. Garrison, R. H., Noreen, E. W., Brewer, P. C., \& McGowan, A. (2010). Managerial accounting. Issues in Accounting Education, 25(4), 792-793.

[28]. Bhimani, A., \& Horngren, C. T. (2008). Management and cost accounting (Vol. 1). Pearson Education.

[29]. Davis, C. E., \& Davis, E. (2011). Managerial accounting. John Wiley \& Sons.

[30]. Cox III, J. F., \& Boyd, L. H. (2018). Using the theory of constraints' processes of ongoing improvement to address the provider appointment scheduling system design problem. Health Systems, 135.

[31]. Maynard, R. (2011). Throughput accounting: better thinking-better results. Operations Management, 6, 35-38.

[32]. Zheng, C. W., \& Abu, M. Y. (2019). Application of activity based costing for palm oil plantation. Journal of Modern Manufacturing Systems and Technology, 2, $1-14$. 